\title{
O Uso do Método IDEA na Avaliação de Sustentabilidade da Agricultura Familiar no Município de Ceará-Mirim - $\mathbf{R N}^{1}$
}

\section{Using the IDEA Method for Assessing Family Farm Sustainability at Ceará-Mirim City - RN}

\author{
Luiz Eduardo Lima de Melo \\ Doutorando em Recursos Naturais - PPGRN/UFCG \\ Instituto Federal de Educação, Ciência e Tecnologia do Rio Grande do Norte, \\ Endereço: Av. Senador Salgado Filho, 1559, Tirol, Natal - RN. CEP: 59.015-000. (84) 4005-2636, e-mail: \\ luiz.melo@ifrn.edu.br
}

\section{Gesinaldo Ataíde Cândido}

Doutor e Professor do Programa de Pós-Graduação em Recursos Naturais (Mestrado e Doutorado) Universidade Federal de Campina Grande - Unidade Acadêmica de Administração e Contabilidade Endereço: Rua, Aprígio Veloso, 882, Bairro Universitário, CEP: 58.429-140, Campina Grande, PB, Brasil. Fone: (83) 2101-1000, e-mail: gacandido@uol.com.br

\section{RESUMO}

A agricultura, como qualquer outra atividade humana, deve levar em conta as dimensões econômica, ambiental e social para se manter sustentável. Existe, atualmente, uma necessidade urgente da realização de estudos e pesquisas que considerem os aspectos da sustentabilidade das atividades agrícolas, tendo a agricultura como uma base fundamental para o desenvolvimento sustentável. Nos últimos anos, foram desenvolvidas diversas metodologias de avaliação da sustentabilidade de agroecossistemas, entre elas o método IDEA ("Indicadores de Sustentabilidade das Explorações Agrícolas"), que avalia as práticas agrícolas em três escalas ou dimensões: a "agroambiental", a "socioterritorial" e a "econômica". Este estudo objetivou avaliar, de forma comparativa, os níveis de sustentabilidade existentes nos diferentes sistemas de manejo agrícola familiar praticados no município de Ceará-Mirim - RN. Para tanto, foram selecionadas 30 propriedades familiares, divididas em 3 grupos, de acordo com a sua forma de manejo: 10 propriedades "convencionais", 10 "orgânicas" e 10 "agroecológicas". A coleta de dados foi feita através de entrevistas diretamente com os agricultores. Os resultados obtidos apontaram a dimensão "socioterritorial" como sendo aquela que está limitando a sustentabilidade como um todo nos três grupos de propriedades estudadas. Eles também mostraram que, de forma geral, as propriedades orgânicas são as que apresentam o maior nível de sustentabilidade entre os três modelos produtivos avaliados no município.

PALAVRAS-CHAVE: Sustentabilidade Agrícola. Agricultura Familiar. Método IDEA.

\section{ABSTRACT}

Agriculture, like any other human activity, must take into account the economic, environmental and social dimensions to remain sustainable. Nowadays, there is an urgent need for studies and researches that consider the aspects for sustainability of agricultural activities, taking the agriculture as a fundamental basis for sustainable

\footnotetext{
1 Artigo recebido em 11.04.2013. Reformulado em 29.05.2013. Aceito para publicação em 10.06.2013. Recomendado para publicação por José Ribamar Marques de Carvalho (Editor Científico). Publicado em 17.07.2013.
} 
development. In recent years, several methods have been developed for assessing the sustainability of agroecosystems, including the IDEA (Farm Sustainability Indicators) method, which assesses agricultural practices in three scales or dimensions: "agri-environmental", "socioterritorial" and "economic". This study aimed to assess, in a comparative way, the levels of sustainability of different management systems of family farming practiced at Ceará-Mirim city - RN. Thus, we selected 30 family farms, that were divided into 3 groups according to their management system: 10 "conventional", 10 "organic" and 10 "agroecological" properties. Data collection was done by interviews directly with the farmers. The results indicated the "socioterritorial" dimension as the one that is limiting the sustainability in the three groups of properties studied. They also showed that, in general, the organic farms are those with the highest level of sustainability among the three productive models assessed at the county.

KEY-WORDS: Farm Sustainability. Family Farming. IDEA Method.

\section{INTRODUÇÃO}

No contexto da procura por uma equidade entre as dimensões social, econômica e ambiental do desenvolvimento, a agricultura tem se destacado como uma área crucial e estratégica para discussão e implementação de políticas que visam o chamado desenvolvimento humano sustentável.

Segundo Anglade (1999), a agricultura, como qualquer outra atividade humana, para se manter sustentável, deve levar em conta, simultaneamente, as dimensões "econômica", "ambiental" e "social", ou seja, impõe-se a combinação da eficácia econômica e da gestão racional do meio ambiente e do tecido social. Isto é, deve ser uma atividade economicamente viável, ecologicamente saudável e socialmente equitativa.

Cândido (2010) ressalta que, nas últimas décadas, a agricultura familiar vem sendo revalorizada e reconhecida por muitos especialistas como um espaço privilegiado, colocando-se como uma questão central para a discussão do desenvolvimento agrário em nosso país. Isto, segundo o autor, ocorre por várias razões, entre elas: esta atividade abrange mais de $80 \%$ dos estabelecimentos rurais do país; responde por parcela significativa do valor bruto da produção agropecuária; absorve cerca de 3/4 da população ocupada pela agricultura e é a fonte principal para produtos de consumo massivo da população brasileira.

No Rio Grande do Norte, as pequenas propriedades rurais familiares correspondem a $86 \%$ do total das propriedades agrícolas do estado. A agricultura familiar é responsável por $90 \%$ da produção de arroz no estado, $86 \%$ da de feijão, $61 \%$ da de mandioca e $83 \%$ da produção de milho. No que diz respeito à pecuária, os estabelecimentos familiares são responsáveis por $75 \%$ da criação de suínos, com produção de $64 \%$ do leite de cabra e $45 \%$ do leite bovino (BRASIL, 2006).

No município de Ceará-Mirim, área de estudo deste trabalho, existem 21 projetos de assentamento rural, que ocupam uma área total de 12.946 hectares (BRASIL, 2010). Ceará-Mirim possui uma área territorial de $739,7 \mathrm{Km}^{2}$, sendo o 
terceiro maior município do seu território rural e, segundo censo realizado pelo Instituto Brasileiro de Geografia e Estatística (IBGE), no ano de 2007 a população deste município era de 65.450 habitantes, dos quais 32.503 habitavam a zona rural, ou seja, quase $50 \%$ da população (BRASIL, 2007).

Neste município, são praticados na agricultura familiar três sistemas de manejo distintos: o "convencional", cuja produção é dependente do uso de pesticidas e fertilizantes químicos; o "orgânico", que obedece aos padrões de qualidade estabelecidos pelo Ministério da Agricultura, Pecuária e Abastecimento (MAPA) para produção orgânica; e o "agroecológico", que possui características híbridas dos dois primeiros modelos.

Apesar de sua importância social, econômica e ambiental, pouco se sabe a respeito dos níveis de sustentabilidade da agricultura familiar praticada em nosso país. Esta falta de informações dificulta, sobremaneira, a criação e implementação de políticas públicas específicas para atender às necessidades deste setor.

Várias metodologias de avaliação de sustentabilidade das práticas agrícolas vêm sendo desenvolvidas nos últimos anos ao redor do mundo. Os sistemas de indicadores de sustentabilidade agrícola, como são chamadas estas metodologias, mostram-se capazes de fornecer um diagnóstico sobre como estão se desenvolvendo as práticas no campo, identificando os fatores que possam estar interferindo na sua sustentabilidade.

O método IDEA ("Indicateurs de Durabilité des Explotations Agricoles" ou "Indicadores de Sustentabilidade das Explorações Agrícolas") é um desses sistemas, que trabalha dentro de uma perspectiva agroecológica, avaliando a sustentabilidade das práticas agrícolas em três eixos ou dimensões: a "agroambiental", a "socioterritorial" e a "econômica" (VILAIN, 2000). Segundo este autor, trata-se um método simples, de fácil aplicação e interpretação dos resultados, sendo, portanto, adequado para avaliação da sustentabilidade das práticas agrícolas familiares em nossa área de estudo.

Este trabalho, portanto, teve por objetivo, avaliar, de forma comparativa, os níveis de sustentabilidade existentes nos diferentes sistemas de manejo praticados na agricultura familiar no município de Ceará-Mirim, RN, usando, como instrumento de avaliação, o método ou sistema IDEA de indicadores de sustentabilidade.

Em termos metodológicos, foi feita, inicialmente uma adequação do método original às especificidades da produção agrícola familiar local para, a partir de então, serem coletados os dados primários junto aos agricultores. Foram pesquisadas 30 propriedades, sendo divididas em três grupos: "convencionais", "orgânicas" e "agroecológicas". Após a tabulação dos dados, determinou-se os percentuais de sustentabilidade para cada grupo de propriedades, em cada uma das três dimensões propostas pelo método. 
Além da introdução, constam, ainda, deste trabalho, os seguintes tópicos: fundamentação teórica, procedimentos metodológicos, apresentação e análise dos resultados, considerações finais e referências.

\section{FUNDAMENTAÇÃO TEÓRICA}

\subsection{Desenvolvimento Sustentável}

A partir dos anos 70, houve uma crescente preocupação envolvendo dinâmicas econômicas, sociais e ambientais. De acordo com Van Bellen (2006), surgiu, então, a necessidade de se entender o meio ambiente de forma mais complexa, considerando a manutenção da vida, preocupando-se com modificações ambientais e sociais, além da situação econômica, tornando-se, portanto, inevitável o uso e o aprofundamento de uma discussão sobre um "mundo sustentável".

Segundo Marzall (1999), a primeira referência sobre sustentabilidade que deve ser citada, por ser a mais difundida e por se constituir em um marco na discussão sobre este tema, é a definição encontrada no Relatório Brundtland ("Nosso Futuro Comum"), de 1987: "desenvolvimento sustentável significa atender às necessidades do presente, sem comprometer a capacidade das gerações futuras de atender suas próprias necessidades".

Para Camino e Muller (1993), o termo “sustentabilidade, atualmente, é usado como uma característica do processo ou estado que pode ser mantido em um determinado nível por tempo indefinido". Estes autores apresentam os termos "desenvolvimento sustentável" e "sustentabilidade" como sendo sinônimos.

Verona (2008) vê a sustentabilidade como uma característica multidimensional de um sistema socioambiental. Para este autor, a sustentabilidade se converte, então, em um conceito que deve ser analisado de acordo com o contexto social em que está inserida a avaliação e a implementação de alternativas. Ainda, segundo ele, a operacionalização da sustentabilidade faz parte do entendimento dos agroecossistemas e permite elaboração de novas propostas de desenvolvimento.

Leff (2001) ressalta que a maneira pela qual tem se buscado o desenvolvimento é abrangente, fruto da emergência da questão ambiental e está inserida em um amplo processo de transformações em direção a uma nova racionalidade, a ambiental. Esta racionalidade ambiental, segundo o autor, requer a incorporação de valores do ambiente na ética individual, nos direitos humanos e na norma jurídica, entre outros.

Ao analisar as principais teorias e práticas do desenvolvimento, Mota (2001) o classifica de três maneiras distintas: 1. o desenvolvimento como progresso; 2 . o desenvolvimento como bem estar social e; 3. o desenvolvimento sustentável, que se refere à relação entre homem e natureza, entre produção e consumo e na forma de apoio do Estado. 
Para Martins e Cândido (2010), o debate em torno da sustentabilidade tem se aproximado dessa problemática, levantando a importância da qualidade de vida, vista não apenas do ponto de vista econômico, mas considerando que é resultado da integração de diversos aspectos (socioculturais, econômicos, políticos, ambientais, etc.).

Quando se fala em sustentabilidade, deve-se voltar a atenção para uma das áreas mais críticas do desenvolvimento, a agricultura, por se tratar de um setor essencial à sobrevivência humana, e cujas atividades, desde os primórdios da civilização, vêm causando alterações profundas nos ambientes naturais, gerando os mais diversos impactos ambientais, sociais e econômicos.

\subsection{Agricultura Sustentável}

Segundo Cândido (2010), existe, atualmente, a necessidade da realização de estudos e pesquisas que levem em conta os aspectos da sustentabilidade nas atividades agrícolas, considerando a agricultura como uma base fundamental da sociedade, onde a sua sustentabilidade é de crucial importância para que se atinja a meta de uma sociedade sustentável em sua integralidade.

No entendimento de Gliessman (2001), a agricultura sustentável é um processo que reconhece a natureza sistêmica da produção de alimentos, forragens e fibras, equilibrando com equidade, preocupações relacionadas à saúde ambiental, justiça social e viabilidade econômica entre os diferentes setores da população, incluindo distintos povos e diferentes gerações.

Masera et al. (1999) salientam que alguns atributos básicos são indispensáveis ao se estabelecer uma situação de agricultura sustentável, sendo eles: "produtividade", "estabilidade", "resiliência", "confiabilidade", "adaptabilidade", "equidade" e "autodependência".

Christen (1996) segue esta linha de pensamento, argumentando que a agricultura sustentável deverá ter os seguintes atributos: 1. assegurar a equidade entre gerações; 2 . preservar a base de recursos da agricultura e evitar externalidades ambientais adversas; 3 . proteger a diversidade biológica; 4. garantir a viabilidade econômica da agricultura, melhorando as oportunidades de emprego e preservando as comunidades rurais; 5. produzir alimentos de qualidade adequada para a sociedade; e 6. contribuir para o desenvolvimento sustentável a nível mundial.

Segundo Tisdell (2006), os agrossistemas industrializados modernos geralmente não utilizam a maioria dos atributos propostos por estes autores, bem como outros atributos adotados nos sistemas agrícolas tradicionais (familiares). Ele lembra que os sistemas modernos são caracterizados pela exploração de poucas espécies ou espécies únicas, que não são desenvolvidas localmente, apresentando ciclos de produção abertos, com ambientes de entrada e saída de matéria e energia 
muito grandes, se comparados com os sistemas tradicionais, que apresentam ciclos de produção relativamente fechados.

Lampkin e Padel (1994) destacam que, atualmente, existe uma extensa discussão acerca da sustentabilidade de duas outras modalidades de exploração agrícola, a agricultura "orgânica" e a "não orgânica" ou "convencional". De acordo com estes autores, a demanda por produtos agrícolas orgânicos tem aumentado nos países mais desenvolvidos pelos seguintes motivos: (a) acredita-se que o produto orgânico é mais saudável do que os alimentos produzidos por sistemas agrícolas não orgânicos; (b) atribui-se um alto grau de sustentabilidade à agricultura orgânica em comparação com agroecossistemas que utilizam extensivamente produtos químicos, tais como pesticidas e fertilizantes artificiais; (c) acredita-se que a agricultura orgânica é ambientalmente mais amigável que a agricultura moderna, sendo inclusive menos ameaçadora para a vida selvagem.

Mazoyer e Roudart (2010) lembram que, em 2050, nosso planeta contará com, aproximadamente, 9 bilhões de seres humanos e que, para alimentar as populações sem subnutrição ou carência de nutrientes, a quantidade de produtos vegetais destinados à alimentação dos homens e dos animais terá que dobrar no mundo inteiro.

Portanto, torna-se imprescindível que a construção de um conceito de uma agricultura sustentável, que possa ser reavaliada, renovada e praticada ao longo das futuras gerações, se desenvolva não somente a partir do meio acadêmico, mas também da percepção que os atores sociais locais têm acerca do seu ambiente, levando em conta sua noção de temporalidade, suas necessidades presentes e futuras, ou seja, o seu próprio conceito de qualidade de vida.

\subsection{Indicadores de Sustentabilidade Agrícola}

Segundo Marzall (2000), na última década do século XX, desenvolveu-se o interesse pela busca de indicadores de sustentabilidade por parte de organismos governamentais, não governamentais, institutos de pesquisa e universidades em todo o mundo.

Para esta autora, o evento de referência sobre este tema é a II Conferência Mundial sobre o Meio Ambiente (Rio-92), com a elaboração de seu documento final, a Agenda 21, onde, em seu capítulo 40, é enfatizada a necessidade do desenvolvimento de indicadores de sustentabilidade por parte de cada país, em função de sua realidade.

Conforme van Bellen (2006), o objetivo dos indicadores é agregar e quantificar informações, de modo que sua significância fique mais aparente. Segundo o autor, eles simplificam as informações sobre fenômenos complexos tentando melhorar, com isso, o processo de comunicação. 
De acordo com Camino e Müller (1993), Masera et al. (1999) e Marzall (2000), algumas características importantes devem ser consideradas na definição dos indicadores. O indicador deve: 1 . ser significativo para a avaliação do sistema; 2 . ter validade, objetividade e consistência; 3 . ter coerência e ser sensível a mudanças no tempo e no sistema; 4 . ser centrado em aspectos práticos e claros, fácil de entender; 5 . permitir enfoque integrador, ou seja, fornecer informações condensadas sobre vários aspectos do sistema; 6. ser de fácil mensuração, baseado em informações facilmente disponíveis e de baixo custo; entre outras.

Vários indicadores, ultimamente, têm sido usados, em comum, em pesquisas abordando sustentabilidade de agroecossistemas, entre eles: água, solo, produção de resíduos, produtividade, agrobiodiversidade, mata nativa, nível educacional, saúde humana, estruturas do sistema, uso da terra, rendimento de cultivos, sanidade vegetal e animal, entrada de produtos agrícolas externos, atividades comunitárias, disponibilidade de mão de obra, acesso à terra, comercialização e consumo de energia (CALORIO, 1997; CÁCERES, 2006).

Nos últimos anos, foram desenvolvidas diversas metodologias para avaliação da sustentabilidade de agroecossistemas, que permitem integrar, equilibradamente, as dimensões social, econômica e ambiental. São os chamados modelos ou sistemas de indicadores de sustentabilidade agrícola, capazes de fornecer um diagnóstico fiel acerca de como estão se desenvolvendo as práticas no campo, identificando os fatores que estão interferindo, de forma positiva ou negativa, na sua sustentabilidade.

Masera et al. (1999) esclarecem que, apesar de não existir um conjunto de indicadores que se adequem a todos os agroecossistemas, os mesmos devem possuir algumas características em comum, como por exemplo: serem integradores de informações, fáceis de mensurar, úteis para um grande número de agroecossistemas, estarem diretamente ligados à informação de base, permitirem avaliar mudanças durante o tempo, além de serem objetivos e claros.

O MESMIS (Marco para Evaluación de Sistemas de Manejo de Recursos Naturales incorporando Indicadores de Sustentabilidad), é um sistema de indicadores agrícolas desenvolvido no México por Masera et al. (1999), a partir de uma seleção de critérios de diagnósticos e de indicadores que, possibilitam avaliar o manejo dos recursos naturais, permitindo uma visualização do comportamento de uma unidade rural de uma forma mais ampla. Conforme Verona (2008), os critérios do MESMIS para avaliação de sustentabilidade de agroecossistemas devem contemplar as dimensões ambiental, econômica e social, sendo necessário um conjunto de indicadores que permitam uma avaliação qualitativa e quantitativa.

O Índice de Desenvolvimento Sustentável (IDS), ou "Biograma", desenvolvido na Costa Rica por Sepúlveda (2008), tem como objetivo propor um método que facilite a avaliação de sustentabilidade de projetos e atividades fundamentadas nos 
princípios do desenvolvimento sustentável. Sepúlveda (2008) esclarece que esta metodologia parte para a construção de indicadores como um instrumento com o qual se pode determinar a sustentabilidade, calculando diversos índices de desenvolvimento, correspondentes a cada dimensão de análise e em cada território rural, que, por fim, integrados, formam o Índice de Desenvolvimento Sustentável relativo a cada território, ou mesmo um só índice para todas as regiões analisadas.

O método IDEA (Indicadores de Sustentabilidade das Explorações Agrícolas) é mais um sistema de indicadores, desenvolvido na França por Vilain (2000), com o intuito de avaliar a sustentabilidade das práticas agrícolas naquele país. Uma vez que o IDEA foi a metodologia de avaliação de sustentabilidade usada nesta pesquisa, será feita, a seguir, uma descrição sucinta de sua estrutura e modo operacional.

\subsection{O Método IDEA na Avaliação da Sustentabilidade Agrícola}

Estabelecido na França por uma equipe multidisciplinar, o método IDEA ("Indicateurs de Durabilité des Explotations Agricoles" ou "Indicadores de Sustentabilidade das Explorações Agrícolas") foi destinado aos professores de escolas agrícolas e aos agricultores que desejavam desenvolver suas atividades por meio de sistemas agrícolas sustentáveis (VILAIN, 2000). Matos Filho (2004) lembra que o IDEA teve sua versão teste aplicada em 1999, passando a ser difundido mais largamente a partir do ano 2000.

Jesus (2003) esclarece que o método comporta três eixos, escalas ou dimensões de sustentabilidade independentes e não acumulativas: a "agroambiental", a "socioterritorial" e a "econômica". Ele explica que o método IDEA não apresenta um limite fixo para a sustentabilidade, e as comparações e análises devem ser feitas entre grupos de propriedades de cada região, entre diferentes sistemas de produção.

Conforme Vilain (2008), o método considera como o fator limitante à sustentabilidade a dimensão que apresenta o menor valor, e sobre a mesma devem ser direcionadas as principais medidas corretivas e mitigadoras dos problemas detectados. Para tanto, o IDEA deve ser utilizado ano após ano, avaliando a evolução ou o retrocesso da sustentabilidade de uma propriedade agrícola.

Vilain (2000) lembra que cada indicador utilizado neste método é constituído de um ou mais itens elementares, definindo uma prática (ou uma característica) e contribuindo para o valor final dos indicadores. $\mathrm{O}$ autor diz ainda que o número de unidades de sustentabilidade atribuídas a cada indicador comporta um valor compreendido entre zero (a sustentabilidade mais baixa) e um valor máximo (sustentabilidade excelente).

Segundo Vieira (2005), o método IDEA é construído a partir de indicadores que sinalizam uma tendência na direção de um ou mais objetivos da agricultura durável. Ele esclarece que os objetivos do eixo agroambiental referem-se aos 
princípios agronômicos da agricultura integrada, próximos dos princípios da agroecologia, devendo permitir boa eficiência econômica, mas com custo ambiental compatível. Já o eixo socioterritorial está ligado com os objetivos sociais da durabilidade, enquanto que o eixo econômico caracteriza a natureza empreendedora do sistema técnico.

Vilain (2008) explica que as dimensões agroambiental, socioterritorial e econômica da produção agrícola são descritas, respectivamente, por 18, 18 e 6 indicadores. Ainda, de acordo com o autor, a combinação dos indicadores é que caracteriza o sistema, e não os valores de um indicador ou de um grupo de indicadores, os quais não possuem nenhum sentido se considerados isoladamente.

No Brasil, alguns autores, ao fazerem uso deste método, tiveram de adaptá-lo às especificidades das produções agrícolas locais. Jesus (2003), por exemplo, fez uma aplicação do método IDEA em quinze propriedades agrícolas de diferentes regiões do estado do Rio de Janeiro, com diferentes sistemas de manejo agrícola (agricultura intensiva e familiar, convencional e orgânica), sendo necessárias algumas adaptações, dadas as grandes diferenças socioeconômicas, ambientais, culturais e tecnológicas em relação à realidade francesa.

Vieira (2005), ao aplicar o IDEA na Zona da Mata mineira, selecionou três propriedades agrícolas familiares com características produtivas distintas (agricultura convencional e orgânica), utilizando alguns cálculos e modificações que haviam sido efetuadas por Jesus (2003), devido às semelhanças com as condições encontradas no estado do Rio de Janeiro.

Já Tavares (2004), a partir do referencial teórico e dos modelos de indicadores existentes, desenvolveu um método de análise da sustentabilidade baseado no IDEA, com o objetivo de avaliar a situação do sistema agrário da citricultura familiar do tipo convencional em Sergipe, levando em conta quatro contextos ou dimensões: "socioterritorial", "socioeconômico", "gestão agrícola" e "uso dos recursos naturais".

Neste trabalho, optou-se pela utilização do método IDEA como instrumento de avaliação da sustentabilidade das práticas da agricultura familiar, uma vez que se trata de uma metodologia de trabalho objetiva, muito simples e de fácil reprodução e utilização por pesquisadores, técnicos agrícolas e, inclusive, pelos próprios agricultores.

Além disso, como ele foi criado, inicialmente, com o intuito de avaliar a sustentabilidade de práticas agrícolas agroecológicas, mostra-se, portanto, adequado para fazer uma avaliação comparativa entre os diferentes sistemas de manejo existentes no município, que são desenvolvidos nas propriedades convencionais, agroecológicas e orgânicas. 


\section{PROCEDIMENTOS METODOLÓGICOS}

\subsection{Contextualização da Área de Estudo}

O município de Ceará-Mirim, área de estudo deste trabalho, localiza-se na microrregião do Litoral Nordeste, na mesorregião do Leste Potiguar, estando inserido no Território Rural do Mato Grande. Nele, existem 21 projetos de assentamento rural, que ocupam uma área total de 12.946 hectares (BRASIL, 2010).

Segundo censo realizado pelo Instituto Brasileiro de Geografia e Estatística (IBGE), no ano de 2007 a população deste município era de 65.450 habitantes, dos quais 32.503 habitavam a zona rural. Ceará-Mirim possui uma área territorial de $739,7 \mathrm{Km}^{2}$, sendo o terceiro maior município do seu território (BRASIL, 2007).

Neste município, as propriedades familiares realizam sua produção agrícola através de três sistemas de manejo distintos: o "convencional", o "orgânico", e o "agroecológico". Para fins desta pesquisa, considerou-se como sistema de manejo "convencional" aquele cuja produção agrícola ainda é dependente do uso de agroquímicos (pesticidas e fertilizantes químicos). Definiu-se como sistema de manejo "orgânico" aquele que busca estar em total conformidade com os padrões estabelecidos pelo Ministério da Agricultura, Pecuária e Abastecimento (MAPA) para produção orgânica. Já o sistema de manejo "agroecológico" seria aquele que não se enquadra em nenhuma das classificações anteriores, possuindo características híbridas dos sistemas convencional e orgânico.

As propriedades familiares orgânicas existentes em Ceará-Mirim realizam sua produção nos moldes do programa PAIS (Produção Agroecológica Integrada Sustentável), recebendo treinamento do SEBRAE (Serviço Brasileiro de Apoio às Micro e Pequenas Empresas). As demais propriedades familiares do município fazem sua produção de forma convencional ou de forma agroecológica.

No que se refere à agricultura convencional intensiva neste município, destacam-se as culturas da banana, abacaxi, cana de açúcar e mandioca. Quanto à agricultura familiar, são produzidos, principalmente, os seguintes alimentos: coentro, alface, rúcula, pimentão, couve, hortelã, tomate, quiabo, beterraba, berinjela, macaxeira, batata, banana, maracujá, mamão, coco e acerola.

\subsection{População e Amostra}

Apesar de diferirem quanto à sua principal característica de manejo, que é o uso ou não de agroquímicos em seus cultivos, os três tipos de propriedades familiares existentes no município possuem várias características em comum, o que lhes confere um alto grau de homogeneidade em suas práticas agrícolas. Entre estas características, podemos citar: todas elas têm a "hortifruticultura" como atividade 
agrícola predominante; possuem uma área de cultivo de até 2 hectares; apresentam a predominância de um tipo de hortaliça nos cultivos, no caso, o "alface"; utilizam mão de obra estritamente familiar.

Por este motivo, e também pelo fato de que, até o momento, não existem dados precisos acerca do número total de unidades agrícolas familiares existentes em Ceará-Mirim, optou-se por se realizar uma amostragem não probabilística intencional, onde foram pesquisadas 30 propriedades familiares, sendo assim divididas: 10 "convencionais", 10 "agroecológicas" e 10 "orgânicas".

O processo de amostragem abrangeu 15 dos 21 assentamentos existentes no município, como uma forma de aumentar o grau de representatividade das amostras em relação à população total de produtores familiares.

\subsection{Coleta de Dados}

A pesquisa foi realizada através de um levantamento de dados primários acerca das diferentes formas de manejo agrícola praticadas nas propriedades familiares do município. A coleta dos dados foi realizada nas propriedades, na forma de uma entrevista do tipo "estruturada", diretamente com os agricultores, utilizando-se um formulário com perguntas fechadas, apresentadas de forma clara e objetiva.

\subsection{Variáveis da Pesquisa}

$\mathrm{Na}$ última versão publicada do método IDEA, Vilain (2008) avalia a sustentabilidade das práticas agrícolas, em suas diferentes dimensões, utilizando-se da seguinte estrutura: 3 componentes e 18 indicadores na dimensão "agroambiental", 3 componentes e 18 indicadores também na dimensão "socioterritorial", e 4 componentes e 6 indicadores na dimensão "econômica", perfazendo, respectivamente, em cada dimensão, uma pontuação máxima de 147, 109 e 100 pontos, que são, depois, convertidos em percentuais de sustentabilidade.

Nas tabelas 1, 2 e 3 são apresentados os "componentes" e "indicadores" que foram usados na avaliação da sustentabilidade da agricultura familiar no município de Ceará-Mirim, em suas três dimensões, com suas pontuações máximas, após a sua adequação às especificidades da agricultura local.

Tabela 1: Componentes e indicadores usados na avaliação da sustentabilidade "agroambiental" da agricultura familiar em Ceará-Mirim.

\begin{tabular}{|c|l|c|}
\hline Componentes & \multicolumn{1}{|c|}{ Indicadores } & $\begin{array}{c}\text { Pontuação } \\
\text { Máxima }\end{array}$ \\
\hline \hline \multirow{2}{*}{$\begin{array}{c}\text { Diversidade } \\
\text { Local }\end{array}$} & Diversidade vegetal & 22 \\
\cline { 2 - 3 } & Diversidade Animal & 10 \\
\hline
\end{tabular}

REUNIR - Revista de Administração, Contabilidade e Sustentabilidade ISSN: 2237-3667 - Vol.3, no 2, Mai./Ago., p. 1-19, 2013. 


\begin{tabular}{|c|c|c|}
\hline & $\begin{array}{l}\text { Valorização e conservação do patrimônio genético } \\
\text { local }\end{array}$ & 12 \\
\hline \multirow{4}{*}{$\begin{array}{l}\text { Organização do } \\
\text { Espaço }\end{array}$} & Padrões de cultivo & 10 \\
\hline & Dimensão das parcelas cultivadas & 10 \\
\hline & Usos dos resíduos orgânicos & 6 \\
\hline & Medidas de proteção do patrimônio natural & 10 \\
\hline \multirow{6}{*}{$\begin{array}{l}\text { Práticas } \\
\text { Agrícolas }\end{array}$} & Fertilização & 12 \\
\hline & Gestão dos efluentes orgânicos & 3 \\
\hline & Pesticidas & 12 \\
\hline & Proteção do solo & 4 \\
\hline & Gestão dos recursos hídricos & 6 \\
\hline & Dependência energética & 6 \\
\hline
\end{tabular}

Fonte: Adaptado de Vilain (2008).

Tabela 2: Componentes e indicadores usados na avaliação da sustentabilidade "socioterritorial" da agricultura familiar em Ceará-Mirim.

\begin{tabular}{|c|l|c|}
\hline Componentes & \multicolumn{1}{|c|}{ Indicadores } & $\begin{array}{c}\text { Pontuação } \\
\text { Máxima }\end{array}$ \\
\hline \hline \multirow{4}{*}{$\begin{array}{c}\text { Qualidade dos } \\
\text { Produtos e da Região }\end{array}$} & Qualidade dos alimentos & 12 \\
\cline { 2 - 3 } & Valorização do patrimônio e da paisagem & 6 \\
\cline { 2 - 3 } & Gestão dos resíduos não orgânicos & 4 \\
\cline { 2 - 3 } & Integração social & 8 \\
\hline \multirow{4}{*}{$\begin{array}{c}\text { Smpregos e } \\
\text { Serviços }\end{array}$} & Valorização da venda local & 8 \\
\cline { 2 - 3 } & Serviços e pluriatividade & 4 \\
\cline { 2 - 3 } & Contribuição à geração de empregos & 6 \\
\cline { 2 - 3 } & Trabalho coletivo & 3 \\
\cline { 2 - 3 } & Sustentabilidade provável & 10 \\
\hline \multirow{3}{*}{$\begin{array}{c}\text { Ética e } \\
\text { Humanolvimento }\end{array}$} & Educação e capacitação profissional & 5 \\
\cline { 2 - 3 } & Intensidade do trabalho & 3 \\
\cline { 2 - 3 } & Qualidade de vida & 10 \\
\cline { 2 - 3 } & Isolamento & \\
\cline { 2 - 3 } & Saúde e segurança do trabalhador & 5 \\
\hline
\end{tabular}

Fonte: Adaptado de Vilain (2008).

Tabela 3: Componentes e indicadores usados na avaliação da sustentabilidade "econômica" da agricultura familiar em Ceará-Mirim.

\begin{tabular}{|c|l|c|}
\hline Componentes & \multicolumn{1}{|c|}{ Indicadores } & $\begin{array}{c}\text { Pontuação } \\
\text { Máxima }\end{array}$ \\
\hline \hline \multirow{2}{*}{$\begin{array}{l}\text { Viabilidade } \\
\text { Econômica }\end{array}$} & Viabilidade econômica & 25 \\
\cline { 2 - 3 } & Taxa de especialização econômica & 10 \\
\hline \multirow{2}{*}{ Independência } & Autonomia financeira & 15 \\
\cline { 2 - 3 } & Sensibilidade às cotas e subsídios & 10 \\
\hline Eficiência & Eficiência do processo produtivo & 25 \\
\hline
\end{tabular}

Fonte: Adaptado de Vilain (2008). 
Na versão adaptada que foi aplicada em Ceará-Mirim, alguns dos indicadores da versão oficial tiveram de ser excluídos, por não serem representativos da realidade das práticas agrícolas desenvolvidas no município. Ao mesmo tempo, novos parâmetros de sustentabilidade foram inseridos nos indicadores restantes, com o intuito de torna-los mais sensíveis e relevantes no tocante ao contexto local, possibilitando uma maior eficiência no processo de avaliação.

Mesmo buscando adaptar o IDEA às particularidades locais, esta pesquisa teve o cuidado de tentar se manter o mais fiel possível à estrutura original do método, evitando, portanto, descaracterizá-lo. A proporcionalidade entre as pontuações máximas possíveis de serem obtidas em cada dimensão da sustentabilidade, bem como entre os seus diferentes componentes, foi mantida o mais próximo possível da versão oficial de Vilain (2008), garantindo-se, assim, a manutenção do enfoque predominantemente agroecológico proposto pelo autor do método.

\section{APRESENTAÇÃO E ANÁLISE DOS RESULTADOS}

Após a realização das entrevistas e aplicação dos formulários de coleta de dados junto aos agricultores nas 30 propriedades familiares pesquisadas, as informações obtidas foram tabuladas e convertidas em valores absolutos, respeitando-se as pontuações máximas de cada um dos 32 indicadores de sustentabilidade apresentados nas tabelas 1, 2 e 3. Em seguida, para cada propriedade, realizou-se o somatório dos valores dos indicadores obtidos em cada dimensão, chegando-se a três valores finais, que foram convertidos em percentuais de sustentabilidade.

A partir dos percentuais ou níveis de sustentabilidade encontrados em cada propriedade, nas três dimensões estudadas, calculou-se os valores médios de sustentabilidade, representativos dos diferentes sistemas de manejo pesquisados: "convencional", "agroecológico" e "orgânico". Os gráficos 1 e 2 apresentam os valores médios percentuais encontrados nos três grupos de propriedades pesquisados.

Segundo Vilain (2008), o fator limitante da sustentabilidade de um agroecossistema seria a dimensão que apresenta o menor valor ao final do processo de avaliação, e sobre a qual devem ser direcionadas ações no sentido de minimizar ou corrigir os problemas que possam estar ocorrendo.

O gráfico 1 mostra, de forma clara, que a dimensão "socioterritorial" foi a que apresentou o menor valor percentual nos três grupos de propriedades estudadas, sendo, portanto, a dimensão mais vulnerável no que diz respeito à sustentabilidade como um todo. Esta dimensão foi avaliada utilizando-se três componentes e quatorze indicadores de sustentabilidade, que foram apresentados no quadro 2. 
No que se refere à sustentabilidade de um sistema de manejo agrícola, o ideal é que haja um equilíbrio entre as dimensões ambiental, social e econômica. Neste caso, como mostra a figura 1, o grupo das propriedades "orgânicas" é o que mais se aproxima deste objetivo, por apresentar uma maior proporcionalidade entre as dimensões avaliadas. Já nos dois outros grupos estudados, das propriedades "convencionais" e "agroecológicas", observa-se uma maior disparidade da dimensão econômica em relação às demais.

As propriedades orgânicas também se destacaram das demais pelo elevado valor encontrado em sua sustentabilidade agroambiental, o que, de certa forma, já era esperado, uma vez que, neste modelo de produção, são priorizadas as práticas agroecológicas.

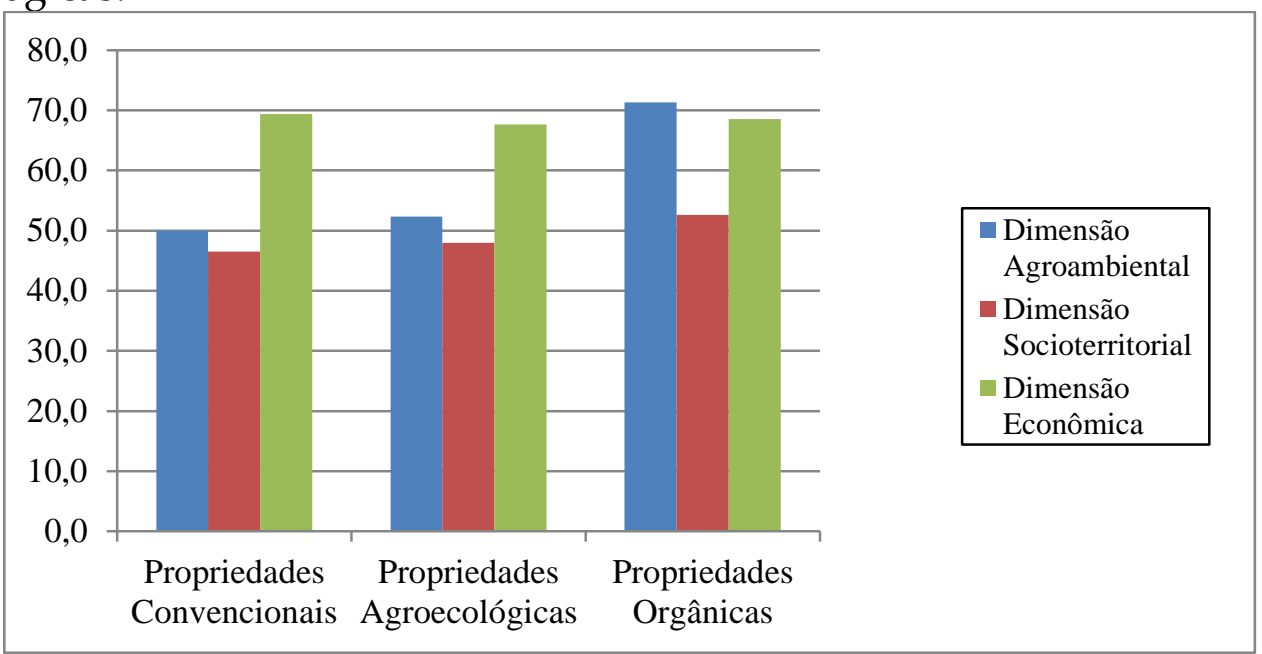

Gráfico 1: Percentuais médios de sustentabilidade encontrados em cada dimensão, nos diferentes sistemas de manejo agrícola.

Fonte: Pesquisa de campo, 2012.

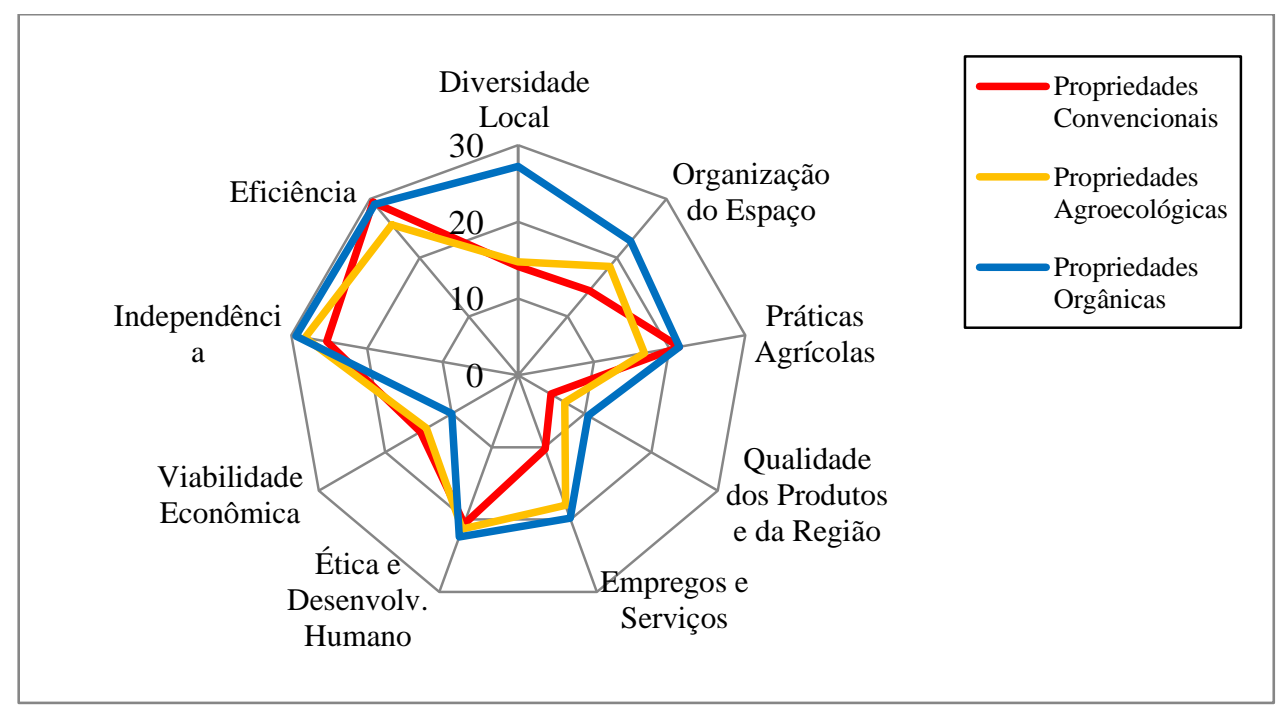

Gráfico 2: Percentuais médios de sustentabilidade encontrados em cada componente das dimensões "agroambiental", "socioterritorial" e "econômica".

Fonte: Pesquisa de campo, 2012. 
O gráfico 2 apresenta os percentuais médios de sustentabilidade encontrados nos diferentes componentes de cada uma das três dimensões avaliadas. Os indicadores de sustentabilidade existentes em cada componente apresentados nas tabelas 1, 2 e 3. Novamente, constata-se que o grupo das propriedades orgânicas é o que apresenta os maiores valores percentuais de sustentabilidade, bem como um maior equilíbrio entre os diversos componentes.

Provavelmente, esse equilíbrio entre as dimensões e componentes da sustentabilidade encontrado nas propriedades orgânicas se deva à homogeneidade de suas características produtivas. Essas propriedades, para serem certificadas, tiveram de se adequar às exigências técnicas do Ministério da Agricultura, Pecuária e Abastecimento, através do programa PAIS do SEBRAE, o que não aconteceu nas propriedades convencionais e agroecológicas, que não possuem ainda uma padronização de suas práticas agrícolas.

Analisando-se o gráfico 2, observa-se uma maior semelhança nos valores dos componentes entre as propriedades convencionais e as agroecológicas, fato que já havia sido constatado no gráfico 1 em relação às dimensões. No que diz respeito, porém, ao equilíbrio entre os componentes, percebe-se que as propriedades agroecológicas se aproximam mais das orgânicas.

Enquanto o gráfico 1 mostra um cenário geral de sustentabilidade, comparando os diferentes sistemas de manejo entre si, o gráfico 2 permite que se tenha uma visão pormenorizada de cada aspecto avaliado nos diferentes tipos de propriedades agrícolas, possibilitando que sejam identificados os fatores que estão interferindo, de forma positiva ou negativa, no desenvolvimento sustentável de suas práticas.

Por exemplo, nos três grupos de propriedades estudadas, o aspecto que está limitando a sua sustentabilidade é a "qualidade dos produtos e da região", componente que faz parte da dimensão socioterritorial. Já nas propriedades orgânicas, além deste, surge o componente "viabilidade econômica" como outro fator limitante de sua sustentabilidade.

Teoricamente, era de se esperar que as propriedades convencionais apresentassem uma sustentabilidade econômica bem superior às demais. Na prática, no entanto, o que se constatou em Ceará-Mirim foram valores percentuais bem próximos entre os três grupos de propriedades estudados.

\section{CONSIDERAÇÕES FINAIS}

Apesar de desenvolvido, originalmente, para avaliar as práticas agrícolas francesas, o método IDEA tem se mostrado passível de adaptações e utilização por pesquisadores no Brasil, em diferentes regiões e contextos socioeconômicos variados. 
Em Ceará-Mirim, a versão adaptada do IDEA mostrou-se capaz de avaliar, comparativamente, a sustentabilidade das práticas agrícolas familiares nas diferentes formas de manejo agrícola praticadas no município.

Os resultados obtidos apontaram a dimensão "socioterritorial" como sendo aquela que está limitando a sustentabilidade como um todo, nos três grupos de propriedades estudadas, sendo, portanto, necessárias ações por parte do poder público, ou dos próprios agricultores, que venham a corrigir ou amenizar os entraves ao desenvolvimento de suas práticas agrícolas.

De forma geral, abrangendo as três dimensões avaliadas, o grupo das propriedades "orgânicas" foi o que apresentou o maior nível de sustentabilidade, com destaque para a dimensão agroambiental. Foi, também, o grupo que apresentou o maior equilíbrio entre as diferentes dimensões e entre os seus componentes, o que, teoricamente, representa uma maior probabilidade dessas propriedades se manterem produtivas e viáveis ao longo do tempo.

O município de Ceará-Mirim possui uma forte vocação para a agricultura familiar, o que faz com que ele se destaque em número de assentamentos e propriedades rurais familiares entre os demais municípios do Território do Mato Grande. Daí a importância de estudos como este para a localidade, uma vez que os resultados obtidos podem vir a subsidiar a criação e/ou o fortalecimento de políticas públicas voltadas à manutenção e ao desenvolvimento desse tipo de modelo fundiário.

Como sugestão para futuros estudos envolvendo o método IDEA, recomendase que, além de avaliações transversais comparativas, como a realizada neste trabalho, sejam feitas avaliações longitudinais periódicas, que podem, inclusive, ser realizadas pelos próprios agricultores, como uma forma prática de se verificar a ocorrência ou não de variações nos níveis de sustentabilidade dessas propriedades, ano após ano.

\section{REFERÊNCIAS}

ANGLADE, J. Agriculture durable et écologie: les indicateurs de durabilitè de la IDEA. Mèmorie de maîtrese de biologie dês organismes à L'Université d'Orsay (Paris-Sud XI), 1999.

BRASIL. Instituto Brasileiro de Geografia e Estatística (IBGE). Censo Agropecuário. 2006.

BRASIL. Instituto Brasileiro de Geografia e Estatística (IBGE). Censo Demográfico. 2007. 
BRASIL. Ministério do Desenvolvimento Agrário. Plano Territorial de Desenvolvimento Rural Sustentável - PTDRS - Território do Mato Grande - RN. 2010.

CÁCERES, D. M. Agrobiodiversity and technology in resource-poor farms. Interciencia, vol.31, n.6, jun. 2006, p. 403-410.

CALORIO, C. M. Análise de sustentabilidade em estabelecimentos agrícolas familiares no Vale do Guaporé - MT. Dissertação de mestrado. Mato Grosso, Cuiabá: Faculdade de Agronomia e Veterinária da Universidade Federal do Mato Grosso, 1997. 95p.

CAMINO, R. \& MÜLLER, S. Sostenibilidad de la agricultura y los recursos naturales: bases para establecer indicadores. San José: IICA, 134 p. (Serie de Documentos de Programas IICA. 38). 1993.

CÂNDIDO, G. A. Rede de estudos e pesquisas em sistemas de indicadores de sustentabilidade para agroecossistemas baseados em práticas de agricultura familiar e da agricultura baseadas nos princípios da revolução verde no nordeste brasileiro. Projeto de pesquisa apresentado para avaliação e julgamento em conformidade Edital CNPq 022/2010). Campina Grande - PB, 2010.

CHRISTEN, O. Sustainable agriculture - history, concept and consequences for research, education and extension. Berichte Uber Landwirtschaft, vol. 74, n. 1, 1996, p.66-86.

GLIESSMAN, S. R. Agroecologia: processos ecológicos em agricultura sustentável. 2 ed. Porto Alegre: Ed. Universidade/UFRGS, 2001. 653p.

JESUS, E. L. Avaliação da sustentabilidade de propriedades agrícolas do Estado do Rio de Janeiro, utilizando o método IDEA. Tese de Doutorado em Agronomia, Ciência do Solo. Seropédica: UFRRJ, 2003.

LAMPKIN, N.H. \& PADEL, S. The Economics of Organic Farming: An Internacional Perspective. Wallingford, UK: CABI. 1994.

LEFF, E. Epistemologia ambiental. Ed. Cortez. São Paulo. 2001.

MARTINS, M.F. \& CÂNDIDO, G.A. Índices de desenvolvimento sustentável para localidades: uma proposta metodológica de construção e análise. In: CÂNDIDO, G.A.(org.). Desenvolvimento Sustentável e Sistemas de Indicadores de 
Sustentabilidade. Editora da Universidade Federal de Campina Grande. Campina Grande - PB, 2010.

MARZALL, K. Indicadores de sustentabilidade para agroecossistemas. Dissertação de Mestrado em Fitotecnia - Universidade Federal do Rio Grande do Sul- UFRGS. Porto Alegre. 1999.

MARZALL, K., ALMEIDA, J. Indicadores de Sustentabilidade para Agroecossistemas: Estado da arte, limites e potencialidades de uma nova ferramenta para avaliar o desenvolvimento sustentável. Cadernos de Ciência \& Tecnologia, Brasília, v.17, n.1, jan./abr. 2000, p .41-59.

MASERA, O., ASTIER, M. \& LÓPEZ-RIDAURA, S. Sustentabilidad y Manejo De Recursos Naturales: el marco de evaluación MESMIS. México: Mundi-Prensa, 1999. 109 pp.

MATOS FILHO, A. M. Agricultura orgânica sob a perspectiva da sustentabilidade: Uma análise da região de Florianópolis - SC, Brasil. Dissertação de Mestrado. Universidade Federal de Santa Catarina. Programa De Pós-graduação em Engenharia Ambiental. 2004.

MAZOYER, M. \& ROUDART, L. História das agriculturas no mundo: do neolítico à crise contemporânea. São Paulo. Editora UNESP; Brasília, DF: NEAD, 2010.

MOTA, C. R. As principais teorias e práticas de desenvolvimento. In: BURSTYN, Marcel (Org.). A difícil sustentabilidade: política energética e conflitos ambientais. 1. ed. Rio de Janeiro: Garamond, 2001, p. 27-40.

SEPÚLVEDA, S. S. Biograma: metodología para estimar el indice de desarrollo sostenible de territorios. San José, C.R.: IICA, 2008.

TAVARES, E. D. Da agricultura moderna à agroecológica: análise da sustentabilidade de sistemas agrícolas familiares. Tese de Doutorado. Centro de Desenvolvimento Sustentável. Universidade de Brasília - UnB, 2004.

TISDELL, C. A. Sustainable agriculture. In: ATKINSON, G.; DIETZ,S.; NEUMAYER,E. Handbook of sustainable development. Great Britain: MPG Books Ltd., Bodmin, Cornwall, 2006. 
VAN BELLEN, H. M. Indicadores de Sustentabilidade: uma análise comparativa. Editora FGV. Rio de Janeiro. 2006.

VERONA, L. A. F. Avaliação de sustentabilidade em agroecossistemas de base familiar e em transição agroecológica na região Sul do Rio Grande do Sul. Tese de Doutorado. Programa de Pós-Graduação em Agronomia.Universidade Federal de Pelotas. Pelotas - RS, 2008.

VIEIRA, M. S. C. Aplicação do método IDEA como recurso didático-pedagógico para avaliação da sustentabilidade de propriedades agrícolas no município de Rio Pomba - MG. Dissertação de Mestrado. Programa de Pós-Graduação em Educação Agrícola. Universidade Federal Rural do Rio de Janeiro. 2005.

VILAIN, L. La méthode IDEA: Indicateurs de durabilité des explotations agricoles: Guide d'utilisation. 1 ère édition. Editions Educagri, Dijon, France, 2000. 100 p.

VILAIN, L. La méthode IDEA: Indicateurs de durabilité des explotations agricoles: Guide d'utilisation. 3 ème édition. Editions Educagri, Dijon, France, 2008. 100 p. 